omission in the simulation literature. This refers to the neglect of potentialities of simulation as a scientific research technique enabling a sophisticated and rigorous approach to analyzing "simulation models." I wished to point out that relatively too much effort has at times been invested in the modeling stage, while neglecting simulation as a model analysis technique. Thus, Schultz and Sullivan may disagree with my definition and propose an alternative which may be more useful for their purpose. (Although it seems that their five-point definition is not strictly in line with Aristotle's advice to definition makers.)

It seems that part of their misinterpreting my argument stems from our different disciplinary backgrounds. I used the operations researcher's approach (see, for example, Hillier and Lieberman's definition in their "Introduction to Operations Research" [Holden Day, 1967]: "Simulation typically is nothing more or less than the technique of performing sampling experiments on the model of the system" [p. 440]) which, I believe, should be that of the social scientist as well. Hence, my implicit assumption concerning experimentation with quantitative models, for whose solution computer simulation is an appropriate technique. (Pencil and paper or a desk calculator are other possibilities, but one would not recommend them too often in this day and age.) Surely, if one deals with a conceptual model, expressed in verbal terms or general symbols, some of my remarks are presently irrelevant. In the latter case, the word "simulation" assumes a different connotation, closer to Schultz and Sullivan's definition, in the same sense that a word such as "significance" has a different meaning in statistical theory as compared to everyday usage.

\author{
-Mordechai Shechter \\ Technion \\ Haifa, Israel
}

\title{
Comments on "Simulation and the City"
}

- In the December 1970 issue of this journal (pp. 411428), Berger, Boulay, and Zisk have outlined some general difficulties which in their opinion have slowed the development of simulation as a method for the scientific study of urban society (p. 412). Although I accept, confirmed by my personal experiences gained in the United States, the authors' 
conclusion of basic intellectual difficulties being responsible for this situation (p. 413), I disagree with several of their interpretations. In my view, some of their statements lead to an increase in the general confusion and disagreement in this field instead of facilitating a reduction of it, and I would like to reply to these authors with the following arguments:

(1) Presupposition for any simulation of an urban phenomenon or process is its definition as a system, i.e. as a theore tical structure consisting of elements (subsystems), relationships, and orders of action (rules).

(2) Depending on the kind of descriptiveness and determinativeness, different approaches for the simulation of one-and-the-same system have to be provided-e.g., an approach to investigate the unknown relationships or orders of action between elements of an urban system (mainly those between the social, cultural, or political elements and their ecotechnical environment) will differ significantly from an approach that tries to derive optimal solutions from a system completely determined.

(3) An excellent and, in my view, still valid description and determination of such different approaches is presented in an early RAND publication by Geisler, Haythorn, and Steger (1962: 5-8; see also Steger, 1965). These authors define a continuum of systems analysis techniques ranging from least to most abstract:

\begin{tabular}{l|l|l|l|l|l}
\hline $\begin{array}{l}\text { Real } \\
\text { World }\end{array}$ & $\begin{array}{l}\text { Observation } \\
\text { from Real } \\
\text { World }\end{array}$ & $\begin{array}{l}\text { One-to-One } \\
\text { Simulation }\end{array}$ & $\begin{array}{l}\text { Game } \\
\text { Simulation }\end{array}$ & $\begin{array}{l}\text { All- } \\
\text { Computer } \\
\text { Simulation }\end{array}$ & $\begin{array}{l}\text { Mathemat- } \\
\text { ical } \\
\text { Analysis }\end{array}$ \\
\hline
\end{tabular}

Increasing Degree of

Abstraction and Formalization

(4) The three simulation techniques defined by the terms One-to-One Simulation, Game Simulation, and All-Computer Simulation (p. 413. Ray and Duke use the terms Gaming, Gaming Simulation, and Simulation; the previous editor of this journal has employed the terms Man Simulation, Man-Machine Simulation, and All-Machine Simulation [Inbar, 1970: 4]) differ significantly in relation to the type of initial empirical bases, of research approach and procedures, and of results obtainable. ${ }^{1}$ The often cited statement of Abt that all games are simulations, but not all simulations are games (p. 416) does not provide any further understanding since it neglects completely the contribution of the formal "Theory of Games" to the techniques of all-computer simulation and mathematical analysis. 
(5) Thus, turning to the argumentation of Berger et al. (pp. 414-415), I would conclude:

There is an essential difference between the techniques described by Ray and Duke, and the failure to recognize their identity and efficiency has greatly contributed to the failure of simulation to develop generally adoptable models of urban social forces, ${ }^{2}$ and the choice between these different simulation-types should only be made on the basis of the relation between the objectives of an analysis or design and the kind of initial empirical material available. $^{3}$

(6) These conclusions lead to an assumption of a principal interdependence between the objectives, empirical bases, and techniques of an urban simulation approach, and thus to the request for the investigation of efficient, if not optimal combinations of these three components. Such kind of theoretical concept of a "general appropriateness" of urban simulations could provide an important contribution for the still outstanding comparison and evaluation of past and present activities, which in turn prove to be in my view the inevitable presuppositions for any valid contribution to this field in the future.

\section{-Henning Schran}

Technische Universität

Berlin, Germany

\section{NOTES}

(1) Depending on the occasional ability to abstract and formalize the process investigated, war games (p. 416) have always been based on these three different simulation techniques: the gaming type ("free" game), the all-computer type ("rigid" game), and the hybrid type of gaming simulation.

(2) An instructive example of this failure in the recognition of identity and resulting confusion is presented in the same issue of this journal: the "Genealogy of Utban Simulation Models" (p. 481) shows an assignment of several projects to the sector "Games," which proves to be not valid in relation to the a.m. typology.

(3) This conclusion in no way neglects the influence that costs may have on this decision. From a general theoretical view, however, this influence has to be seen as an exogenous variable to the simulation approach, not as an endogenous one. 


\section{REFERENCES}

GEISLER, M., W. HAYTHORN, and W. STEGER (1962) "Simulation and the logistics systems laboratory." RAND Memorandum 3281, Santa Monica, Calif. INBAR, M. (1970) "Editorial introduction.” Simulation and Games 1 (March). STEGER, W. (1965) "Review of analytic techniques for the CRP." J. of Amer. Institute of Planners 2 (May).

\section{A Reply to Dr. Schran:}

- If we understand Mr. Schran correctly, he diverges from us on only one important point: the usefulness of commonly accepted schemas for classifying simulations.

In our assessment of developments in urban simulation (and, by implication, simulation in social science generally) we took the position that classificatory categories used to differentiate among different techniques for simulating had taken on, perhaps more by default than by design, epistemological status. We will still insist on this point. Granted, simulation techniques may be placed on a continuum which reflects an "increasing degree of abstraction and formalization." The formality or abstractness of a model does not affect the relationship between the referent system and simulation findings. The kinds of knowledge produced by each technique are directly comparable. We would even extend this notion to purely deductive systems such as game theory since they are relevant to social science concerns only as they are "applied."

The structures and processes which social scientists investigate are exactly as "simple" or "complex," as "abstract" or "real" as are the schemes we use to describe and explain them. Thus, a social choice payoff function may be a very "simple" thing for a welfare economist, since the behavior involved may be represented by a "simple" equation. The same social choice behavior may be catastrophically "complex" for another social scientist investigating such an event through, let us say, "gamingsimulation."

We must not let such differences in technique obscure the fact that it is one and the same social process which is being modelled in the above examples. The "real world" referents remain the same. The logic of inquiry applies to both sorts of models in the same way. The results 